\section{Kidney \\ Blood Pressure Research}

Kidney Blood Press Res 2015;40:500-508

\begin{tabular}{l|l}
\hline DOI: $10.1159 / 000368526$ & (c) 2015 S. Karger AG, Basel
\end{tabular}

Published online: October 04, 2015

Accepted: September 07, 2015

\title{
The Effect of Preserved Residual Renal Function on Left Ventricular Structure in Non-Anuric Peritoneal Dialysis Patients
}

\author{
Damir Rebića Mirjana Sabljar Matovinovićc Senija Rašića Petar Kes ${ }^{b} \quad$ Aida \\ Hamzić-Mehmedbašića \\ ${ }^{a}$ Clinic for Nephrology, University Clinical Center of Sarajevo, Bosnia and Herzegovina; bSchool of \\ Medicine University of Zagreb, Croatia
}

\section{Key Word}

Eend-stage renal disease $\bullet$ Residual renal function $\bullet$ Left ventricle $\bullet$ Peritoneal dialysis

\begin{abstract}
Background/Aims: Residual renal function (RRF) has been shown to influence survival of peritoneal dialysis (PD) patients. This study examined the relations between RRF and left ventricular hypertrophy (LVH) before switching on dialysis treatment and observed during 18 months on PD treatment. Methods: A prospective longitudinal study was performed in 50 nonanuric (defined as $>200 \mathrm{~mL}$ urine output in a 24-hour period) PD patients. Echocardiography, RRF and other known risk factors for the increase of LV mass index (LVMi) were determined at study baseline and the end of follow-up. Results: There was $78 \%$ patients with LVH in end-stage renal disease (ESRD) baseline and 60\% at the end of follow-up. RRF at the start of the study showed no significant difference between patients with normal and increased LVMi, as well as in daily collection of urine. After 18 months, patients with decreased LVMi had better RRF, lower CRP and better Kt/N compared to patients with increased LVMi $(p<$ 0.001 ). Patients with better preserved RRF not only had significantly higher total Kt/V, but were less anemic and hypoproteinemic and lesser presence of LVH. Conclusions: PD in non-anuric ESRD patients the first 18 months has a positive effect on the preservation of RRF and partial regression of left ventricular remodeling.
\end{abstract}

Copyright $\odot 2015$ S. Karger AG, Basel

\section{Introduction}

Cardiovascular disease is the leading cause of morbidity and mortality in end-stage renal disease (ESRD) patients on maintenance dialysis. Residual renal function (RRF) has been shown to influence survival of peritoneal dialysis (PD) patients [1]. Wang, in her study demonstrated more adverse cardiovascular, inflammatory, nutritional and metabolic profiles as well as higher mortality in anuric compared to non-anuric PD patients [2]. 


\section{Kidney \\ Blood Pressure Research}

Kidney Blood Press Res 2015;40:500-508

\begin{tabular}{l|l}
\hline DOI: $10.1159 / 000368526$ & (C) 2015 S. Karger AG, Basel
\end{tabular}

Published online: October 04, 2015

www.karger.com/kbr

501

Rebić/Sabljar Matovinović/Rašić/Kes/Hamzić-Mehmedbašić: Residual Renal Function and Peritoneal Dialysis

Cross-section surveys noted up to $80 \%$ of the dialysis patients have a left ventricular (LV) alteration, among which left ventricular hypertrophy (LVH) is the most frequent finding [3].

Advanced age, hypertension, nontraditional cardiovascular risk factors and time on dialysis have been suggested to be some of the strongest risk factors for LVH in these patients. In pre-dialysis patients, the decline in creatinine clearance was associated with an increase in the LV mass index (LVMi) [4]. Regression of LVH was mentioned in dialysis patients after kidney transplantation [5]. These results suggest that the RRF and the biochemical environment in uremia may be important in determining the LV remodeling.

This study was performed to determine the relations, if any, between RRF and LVH before turning on dialysis therapy and after 18 months of PD treatment. Also, the aim of our study was to identify the importance of PD on preservation of the RRF in the first years of dialysis treatment.

\section{Patients and Methods}

\section{Patients}

This prospective longitudinal study included 50 ESRD non-anuric patients (diuresis $>200 \mathrm{ml}$ per day) that were observed for 18 months after the commencement of continuous ambulatory PD (CAPD) treatment. Other than excluding patients with congenital or valvular heart disease, cerebral vascular diseases, patients with underlying active inflammatory disease such as systemic lupus erythematosus, malignancy, as well as patients previously treated with hemodialysis, all non-anuric CAPD patients were included into the study. All examined patients underwent four to five dialysis changes with $2 \mathrm{~L}$ of dialysis solution. Double-chamber bag Stay-Safe ${ }^{\circ}$ Balance system (Fresenius Medical Care, Germany) was available for all including patients. This system utilizes lactate-buffered PD solution in a two-compartment bag offered in the Stay-Safe ${ }^{\circ}$ disconnect system. The formation of glucose degradation product (GDP) is greatly reduced by separating the glucose component of the solution (kept at very low $\mathrm{pH}$ ) from the lactate component of the solution (kept at alkaline $\mathrm{pH}$ ) during sterilization and storage. Immediately before infusion, the seam between the two chambers is opened, and the contents are mixed. The ready-to-use solution has a near-physiological $\mathrm{pH}$, and a greatly reduced amount of GDP.

At the moment of the start trial, all observed patients were without clinical manifestation of heart failure.

The base laboratory assessment included measurement of brain-natriuretic peptide (BNP) as well as serum endothelin-1 (ET-1) and nitric oxide (NO) concentration. The measurement of serum concentration of ET-1 $(\mathrm{pg} / \mathrm{mL})$ was done by the ELISA method (Enzyme immunoassay for the quantitative determination of human endothelin (1-21) in serum, kit Biomedica Medizinprodukte GmbH \& Co KG, Wien). For the determination of concentration of NO in the serum, R\&D System Total Nitric Oxide kit was utilized, while the concentration of $\mathrm{NO}$ was expressed in $\mu \mathrm{mol} / \mathrm{L}$. Blood samples for the determination of concentration of NO and ET-1 were analyzed at the Institute for Biochemistry of the Clinical Hospital Sestre milosrdnice in Zagreb, Croatia.

In all patients, any therapy that can influence the values of monitored laboratory parameters (nitrites, captopril, NSAIDs, heparin, beta2 agonists) were excluded $24 \mathrm{~h}$ before taking blood samples for determination of concentration of ET- 1 and NO. The study was conducted $2 \mathrm{~h}$ after an early morning dialysis change. All records of patients were protected, whereas the study was conducted with the approval of local Ethics Committee and the respect for the rules of ethic principles in medical research. All patients were given their informative consent for the participation in the study.

\section{Echocardiographic assessment}

In all patients echocardiographic parameters were evaluated at the very beginning of dialysis treatment and after 18 months. Echocardiographic assessment was conducted by "Toshiba 270 SSA" device, equipped with the $3.75 \mathrm{MHz}$ frequency sector sonde. All patients were examined with the method of conventional M-mode and two-dimensional echocardiography. The measurement performed by two cardiologists, who were not acquainted with the clinical status of the patients, according to the recommendations of 


\section{Kidney \\ Blood Pressure Research}

Kidney Blood Press Res 2015;40:500-508

\begin{tabular}{l|l}
\hline DOI: $10.1159 / 000368526$ & (C) 2015 S. Karger AG, Basel
\end{tabular}

Published online: October 04, 2015

www.karger.com/kbr

the American Society of Echocardiography. The LV mass was calculated according to the formula of Penn Convention, [6] while the left ventricular mass index (LVMi) was calculated with the division of the left ventricular mass (LVM) with the body surface area. LVH is defined as the LVMi $>131 \mathrm{~g} / \mathrm{m}^{2}$ for males and $>100$ $\mathrm{g} / \mathrm{m}^{2}$ for females. The systolic function of the $\mathrm{LV}$ was assessed by the measurement of ejection fraction (EF). The systolic weakness of $\mathrm{LV}$ is defined as $\mathrm{EF}<50 \%$. The diastolic function of $\mathrm{LV}$ is assessed by determination of the maximum velocity of the early $(\mathrm{E})$ and late $(\mathrm{A})$ phase of ventricular filling and the calculation of the E/A ratio. The diastolic dysfunction of $L V$ is defined as $E / A \leq 1$.

Parameters of Peritoneal Dialysis

The indices of dialysis adequacy were measured after six and eighteen months after the being subjected to PD. Adequacy of dialysis (Kt/Vurea) was calculated from weekly total removed urea mass by daily volume of dialysate and urine (Kt) and divided with urea distribution volume (V). The distribution volume of urea was calculated by using the Watson equation [7].

Residual renal function was estimated as the mean of renal creatinine and renal urea clearance $(\mathrm{mL} /$ $\mathrm{min}$ ) at baseline and at the end of the study period. A simplified peritoneal equilibration test was performed using $4.25 \%$ glucose-based solution to obtain the dialysate to plasma creatinine concentration ratio at 4 hours of dwell (D/P [Cr]). Patients were categorized as high, high-average, and low-average transporters according to criteria of Chung and colleagues [8].

Statistical analysis

All statistical calculations were performed with the SPSS 16 software (version 16.0, SPSS Inc, Chicago, IL). Each value was expressed as the mean $\pm S D$ or as median and interquartile range where appropriate. Significant changes in the variables from baseline to 18 months after PD treatment were tested by paired t-test for the variables that followed normal distribution or by the Wilcoxon signed-rank test for the variables that had skewed distribution. The difference between two groups was analyzed by the MannWhitney test. A multiple regression analysis was applied to examine the relationship between $\mathrm{LV}$ remodeling parameters and a set of clinical and laboratory parameters. Since ET-1, NO, C-reactive protein (CRP), B-type natriuretic peptide (BNP), and age were non-normally distributed in this study, we normalized these data by log transformation before entering a stepwise multiple regression. The significant independent variables were ordered according to their standardized effect, defined as regression coefficient/standard error of the regression (b). $P$ values $<0.05$ were considered statistically significant.

\section{Results}

The characteristics of the study patients are shown in Table 1 . Some $52 \%$ of patients enrolled in our study were diabetics. The underlying cause of ESRD was diabetic nephropathy in $48 \%$, glomerulonephritis in $14 \%$, hypertensive nephrosclerosis in $18 \%$, pyelonephritis in $14 \%$, and not identified in $6 \%$ patients. Overall, $100 \%$ of the patients were using erythropoietin, and $48 \%$ of the patients were receiving ACEI or ARB at the end of the monitoring period. The reason for the decline of percentage of patients taking ACEI/ARB is increasing doses of other antihypertensive agents (e.g. calcium channel blocker) or the normalization of blood pressure in most patients (Table 1).

The comparison of various parameters in relation to changes of LVMI is provided in Table 2. In ESRD patients, LVH was diagnosed in 39 patients (78\%). LVH was observed in $60 \%$ after 18 months on PD treatment. In the study period, LV function was worst in patients with a greater increase in LVMi. On the contrary, patients with normal LVMi had significantly better preserved systolic and diastolic LV function. Daily urine volumes, RRF, Kt/V urea weekly, systolic and diastolic blood pressure (BP) were significantly different between the two groups after 18 months of PD. On the other hand, ET-1 was higher in the group with a greater increase in LVMi. Also, serum albumin was lower in group with the increase of LVMi during the follow-up (Table 2). 


\section{Kidney \\ Blood Pressure Research}

Rebić/Sabljar Matovinović/Rašić/Kes/Hamzić-Mehmedbašić: Residual Renal Function and Peritoneal Dialysis

Table 1. Characteristics of study subjects

Table 2. Clinical, biochemical and dialytic parameters of the groups of patients in relation to changes of left ventricular mass index during the monitoring period

\begin{tabular}{lcc}
\hline \multicolumn{1}{c}{ Characteristic } & \multicolumn{2}{c}{ Value } \\
\cline { 2 - 3 } & Baseline & After 18 months on PD \\
\hline Age (years) (median [IQR])) & $60.5(19-76)$ & \\
Gender (male) n (\%) & $25(50)$ & $16(32)$ \\
Positive smoking history n (\%) & $18(45)$ & \\
Diabetes mellitus n (\%) & $26(52)$ & \\
Cause of ESRD & & \\
Hypertensive nephrosclerosis n (\%) & $9(18)$ & \\
Diabetic nephropathy n (\%) & $24(48)$ & $25.7 \pm 2.2$ \\
Pyelonephritis n (\%) & $7(14)$ & \\
Glomerulonephritis n (\%) & $7(14)$ & \\
Unknown n (\%) & $3(6)$ & \\
BMI (kg/m² mean \pm SD) & $25.9 \pm 3.7$ & \\
Medication use & & $24(10)(60 \pm 20)$ \\
On diuretic n(\%) (mg/daily mean \pm SD) & $36(72)(250 \pm 120)$ & \\
Erythropoietin n (\%) & $36(72)$ & \\
ACEI or ARB n (\%) & $32(64)$ & \\
\hline Abbreviations: BMI, body mass & \\
\hline
\end{tabular}

Abbreviations: BMI, body mass index; ACEI, angiotensin-converting enzyme inhibitor; ARB, angiotensin receptor blocker; IQR, interquartile range.

\begin{tabular}{|c|c|c|c|c|}
\hline \multirow{3}{*}{ Characteristic } & \multicolumn{4}{|c|}{ Left ventricular mass index } \\
\hline & Normal (11) & Increase (39) & Decrease (24) & Increase (26) \\
\hline & \multicolumn{2}{|c|}{ Baseline } & \multicolumn{2}{|c|}{ End of follow-up } \\
\hline LV mass index & $108.7 \pm 13.5$ & $177.3 \pm 27.7^{\mathrm{a}}$ & $119.5 \pm 29.6^{c}$ & $173.75 \pm 35.3^{\text {bd }}$ \\
\hline $\mathrm{EF}(\%)$ & $62.5 \pm 4.6$ & $46.6 \pm 7.1^{\mathrm{a}}$ & $62.37 \pm 8.2$ & $48.38 \pm 6.9$ bd \\
\hline FS $(\%)$ & $34.6 \pm 2.3$ & $27.2 \pm 4.5^{\mathrm{a}}$ & $33.49 \pm 3.2$ & $27.21 \pm 2.6^{b}$ \\
\hline $\mathrm{E} / \mathrm{A}$ ratio & $1.1 \pm 0.1$ & $0.9 \pm 0.1^{\mathrm{a}}$ & $1.14 \pm 0.1$ & $1.02 \pm 0.0^{\mathrm{d}}$ \\
\hline $\mathrm{LAD}(\mathrm{mm})$ & $40.1 \pm 1.2$ & $44.3 \pm 6.1$ & $37.98 \pm 8.5^{c}$ & $44.10 \pm 5.3^{\mathrm{b}}$ \\
\hline LVEDD (mm) & $51.1 \pm 1.6$ & $53.4 \pm 3.9$ & $46.38 \pm 8.8$ & $54.19 \pm 3.2^{b}$ \\
\hline Mean BP (mmHg; mean \pm SD) & $100.0 \pm 16.9$ & $111.8 \pm 13.7^{a}$ & $92.42 \pm 7.5^{c}$ & $98.95 \pm 9.5^{b d}$ \\
\hline Hemoglobin $(\mathrm{g} / \mathrm{l}$; mean $\pm \mathrm{SD})$ & $108.8 \pm 10.7$ & $99.9 \pm 9.4^{\mathrm{a}}$ & $125.1 \pm 10.0^{c}$ & $109.2 \pm 9.6^{\mathrm{d}}$ \\
\hline Serum albumin $(\mathrm{g} / \mathrm{L}$; mean $\pm \mathrm{SD})$ & $34.9 \pm 4.3$ & $29.5 \pm 3.8^{a}$ & $32.0 \pm 2.1$ & $30.5 \pm 2.0^{\mathrm{d}}$ \\
\hline $\mathrm{CRP}(\mathrm{mg} / \mathrm{L} ;$ mean $\pm \mathrm{SD})$ & $5.7 \pm 3.5$ & $13.9 \pm 8.4^{\mathrm{a}}$ & $3.5 \pm 2.7$ & $8.8 \pm 3.2^{b}$ \\
\hline $\mathrm{BNP}(\mathrm{pg} / \mathrm{mL} ;$ median [IQR]) & $58.3(50-197.9)$ & $266.4(117.8-528.8)^{a}$ & $66.5(34.5-79.5)$ & $77.6(67.4-126.5)^{\mathrm{bd}}$ \\
\hline Troponin (ng/ml; median [IQR]) & 0.00 & $0.087(0.019-0.12)$ & $0.001(0.00-0.001)$ & $0.02(0.003-0.05)^{\mathrm{bd}}$ \\
\hline Nitric oxide ( $\mu$ mol/L; median[IQR]) & $63.2(59.7-106.2)$ & $28.5(14.8-46.8)^{a}$ & $58.0(32.8-60.4)^{c}$ & $31.0(14.4-38.4)^{\mathrm{b}}$ \\
\hline Endothelin-1(pg/ml; median[IQR]) & $2.6(2.2-4.0)$ & $7.0(4.1-8.8)^{\mathrm{a}}$ & $3.0(2.1-5.0)$ & $7.4(6.0-19.9)^{\mathrm{bd}}$ \\
\hline Diuresis(mL/day; mean \pm SD) & $750.0 \pm 463.1$ & $487.9 \pm 335.9$ & $836.84 \pm 525.4$ & $291.54 \pm 238.1^{b}$ \\
\hline GFR $\left(\mathrm{ml} / \mathrm{min}\right.$ per $1.73 \mathrm{~m}^{2} ;$ mean $\left.\pm \mathrm{SD}\right)$ & $7.2 \pm 4.2$ & $5.0 \pm 3.5$ & $8.3 \pm 5.3^{c}$ & $4.6 \pm 3.5^{\mathrm{b}}$ \\
\hline \multicolumn{5}{|l|}{ Total weekly Kt/V } \\
\hline$<1.7 \mathrm{n}(\%)$ & 0 & $4(10.3)$ & 0 & $1(3.85)$ \\
\hline $1.7-2.0 \mathrm{n}(\%)$ & 0 & $21(53.8)$ & $7(29.16)$ & $12(46.15)$ \\
\hline$>2.0 \mathrm{n}(\%)$ & $11(100)$ & $14(35.9)$ & $17(70.83)$ & $13(50)$ \\
\hline nPNA (g/kg/day) & $1.1 \pm 0.1$ & $1.0 \pm 0.1^{\mathrm{a}}$ & $1.1 \pm 0.1$ & $1.0 \pm 0.1^{b d}$ \\
\hline Low-average transporters(T) n(\%) & $11(100)$ & $23(59)$ & $22(91.66)$ & $14(53.85)$ \\
\hline High-average T n (\%) & 0 & $9(23.1)$ & $1(4.16)$ & $8(30.77)$ \\
\hline High T n $(\%)$ & 0 & $7(17.9)$ & $1(4.16)$ & $4(15.38)$ \\
\hline 24-hour peritoneal UF (ml) & $970 \pm 440$ & $1010 \pm 480$ & $1000 \pm 320$ & $1050 \pm 260$ \\
\hline 4-hour peritoneal UF (ml) & $190 \pm 120$ & $215 \pm 80$ & $200 \pm 90$ & $220 \pm 110$ \\
\hline \multicolumn{5}{|c|}{$\begin{array}{l}\text { Abbreviations: LVH, left ventricular hypertrophy; EF, ejection fraction; E/A, ratio of early-to-late transmitral flow velocity; FS, } \\
\text { fractional shortening; LAD, left atrium diameter; BP, blood pressure; CRP, C-reactive protein; BNP, B-type natriuretic peptide } \\
\text { GFR, glomerular filtration rate; nPNA, protein equivalent of total nitrogen appearance; UF, ultrafiltration; IQR, interquartile } \\
\text { range. a Significant difference between without and with LVH at baseline. b Significant difference between groups with } \\
\text { decreasing and increasing LVMi after } 18 \text { months of PD. c Significant difference between the group without LVH at baseline } \\
\text { and group with decreasing LVMi after } 18 \text { months of PD. d Significant difference between group with increased LVMi at } \\
\text { baseline and group with increasing LVMi after } 18 \text { months of PD. (Significant differences, } p<0.01 ; p<0.05 \text { ). }\end{array}$} \\
\hline
\end{tabular}




\section{Kidney \\ Blood Pressure Research}

\section{Kidney Blood Press Res 2015;40:500-508}

DOI: 10:1159/000368526

(C) 2015 S. Karger AG, Basel

www.karger.com/kbr

Rebić/Sabljar Matovinović/Rašić/Kes/Hamzić-Mehmedbašić: Residual Renal Function and Peritoneal Dialysis

Table 3. Monitored parameters in relation to the residual renal function in patients before dialysis treatment and after 18 months of PD

\begin{tabular}{|c|c|c|c|c|}
\hline \multirow[t]{2}{*}{ Characteristic } & $\begin{array}{c}\mathrm{GFR}>3 \mathrm{ml} / \mathrm{min} \\
\text { and }>500 \mathrm{ml} \text { daily } \\
\text { urine }(10)\end{array}$ & $\begin{array}{c}\mathrm{GFR}<3 \mathrm{ml} / \mathrm{min} \\
\text { and }<500 \mathrm{ml} \text { daily } \\
\text { urine }(40)\end{array}$ & $\begin{array}{c}\mathrm{GFR}>3 \mathrm{ml} / \mathrm{min} \\
\text { and }>500 \mathrm{ml} \text { daily } \\
\text { urine (22) }\end{array}$ & $\begin{array}{c}\mathrm{GFR}<3 \mathrm{ml} / \mathrm{min} \\
\text { and }<500 \mathrm{ml} \text { daily } \\
\text { urine (28) }\end{array}$ \\
\hline & \multicolumn{2}{|c|}{ Baseline } & \multicolumn{2}{|c|}{ End of follow-up } \\
\hline LVH n (\%) & $7(70)$ & $32(80)$ & $6(27.27)$ & $24(85.7)$ \\
\hline LV mass index & $114.9 \pm 25.9$ & $174.0 \pm 30.9^{a}$ & $122.3 \pm 26.5$ & $172.5 \pm 27.3^{\mathrm{b}}$ \\
\hline $\mathrm{EF}(\%)$ & $62.3 \pm 5.5$ & $47.1 \pm 7.5^{\mathrm{a}}$ & $62.2 \pm 6.5$ & $49.0 \pm 6.6^{\mathrm{bc}}$ \\
\hline FS (\%) & $35.2 \pm 1.8$ & $27.3 \pm 4.4^{a}$ & $34.8 \pm 3.2$ & $29.1 \pm 3.4^{\mathrm{b}}$ \\
\hline E/A ratio & $1.2 \pm 0.0$ & $0.9 \pm 0.1^{\mathrm{a}}$ & $1.1 \pm 0.1$ & $1.0 \pm 0.1^{b}$ \\
\hline $\mathrm{LAD}(\mathrm{mm})$ & $39.6 \pm 1.8$ & $44.3 \pm 5.9^{a}$ & $38.6 \pm 2.6$ & $44.2 \pm 7.3^{\mathrm{b}}$ \\
\hline LVEDD (mm) & $51.2 \pm 1.7$ & $53.3 \pm 3.9$ & $49.6 \pm 1.7$ & $52.0 \pm 9.4^{\mathrm{b}}$ \\
\hline Mean BP (mmHg; mean \pm SD) & $98.78 \pm 15.4$ & $108.77 \pm 13.7^{a}$ & $92.90 \pm 8.0$ & $101.2 \pm 8.7 \mathrm{bc}$ \\
\hline Hemoglobin (g/l; mean \pm SD) & $111.5 \pm 11.5$ & $99.5 \pm 8.6^{\mathrm{a}}$ & $113.4 \pm 10.1$ & $107.4 \pm 6.3^{\mathrm{bc}}$ \\
\hline Serum albumin $(\mathrm{g} / \mathrm{L} ;$ mean \pm SD) & $34.1 \pm 4.2$ & $29.9 \pm 4.2$ & $32.0 \pm 2.9$ & $30.1 \pm 1.9 \mathrm{bc}$ \\
\hline $\mathrm{CRP}(\mathrm{mg} / \mathrm{L} ;$ mean $\pm \mathrm{SD})$ & $4.9 \pm 2.4$ & $14.0 \pm 8.3^{\mathrm{a}}$ & $4.1 \pm 2.7$ & $10.8 \pm 15.2^{\mathrm{b}}$ \\
\hline BNP (pg/mL; median [IQR]) & $59.2(56.7-399.4)$ & $229.6(108.9-489.0)$ & $77.4(50.2-98.2)$ & $152.0(87.5-165.9)^{\mathrm{bc}}$ \\
\hline Troponin (ng/ml; median [IQR]) & $0.0(0.0-0.002)$ & $0.079(0.018-0.12)^{\mathrm{a}}$ & $0.001(0.00-0.003)$ & $0.04 \pm 0.04^{\mathrm{b}}$ \\
\hline Nitric oxide $(\mu \mathrm{mol} / \mathrm{L} ;$ median $[\mathrm{IQR}])$ & $63.5(56.8-106.2)$ & $31.1(15.6-46.9)^{a}$ & $61.7(45.5-98.2)$ & $33.8(20.5-49.1)^{\mathrm{bc}}$ \\
\hline Endothelin-1 (pg/ml; median[IQR]) & $2.8(2.2-4.0)$ & $7.0(4.1-8.8)^{\mathrm{a}}$ & $2.9(2.2-3.8)$ & $6.0(4.7-9.8)^{\mathrm{bc}}$ \\
\hline Diuresis(mL/day; mean \pm SD) & $745.0 \pm 469.3$ & $495.8 \pm 341.3$ & $770.5 \pm 448.0$ & $332.6 \pm 307.7 \mathrm{~b}$ \\
\hline \multicolumn{5}{|l|}{ Total weekly Kt/V } \\
\hline$<1.7$ & 0 & $4(10.0 \%)$ & 0 & $2(8.7 \%)$ \\
\hline $1.7-2.0$ & $1(10 \%)$ & $20(50.0 \%)$ & $1(4.55 \%)$ & $14(60.9 \%)$ \\
\hline$>2.0$ & $9(90 \%)$ & $16(40.0 \%)$ & $21(95.5 \%)$ & $12(42.9 \%)$ \\
\hline nPNA (g/kg/day) & $1.2 \pm 0.1$ & $1.1 \pm 0.1^{\mathrm{a}}$ & $1.1 \pm 0.1$ & $1.1 \pm 0.1$ \\
\hline Low-average transporters (T) n (\%) & $10(100 \%)$ & $24(60.0 \%)$ & $22(100 \%)$ & $15(53.6 \%)$ \\
\hline High-average T n (\%) & 0 & $9(22.5 \%)$ & 0 & $9(32.1 \%)$ \\
\hline High T n (\%) & 0 & $7(17.5 \%)$ & 0 & $4(14.3 \%)$ \\
\hline 24-hour peritoneal UF (ml) & $890 \pm 390$ & $1110 \pm 370$ & $910 \pm 450$ & $1280 \pm 310$ \\
\hline 4-hour peritoneal UF(ml) & $210 \pm 110$ & $290 \pm 260$ & $270 \pm 200$ & $390 \pm 210$ \\
\hline \multicolumn{5}{|c|}{$\begin{array}{l}\text { Abbreviations: LV, left ventricle; LVH, left ventricular hypertrophy; } \mathrm{EF} \text {, ejection fraction; E/A, ratio of early-to-late } \\
\text { transmitral flow velocity; FS, fractional shortening; LAD, left atrium diameter; BP, blood pressure; CRP, C-reactive } \\
\text { protein; BNP, B-type natriuretic peptide; } \mathrm{nPNA} \text {, protein equivalent of total nitrogen appearance, UF, ultrafiltration; IQR, } \\
\text { interquartile range. a Significant difference between groups with GFR }>3 \mathrm{ml} / \mathrm{min} \text { and GFR }<3 \mathrm{ml} / \mathrm{min} \text { at baseline. b } \\
\text { Significant difference between GFR }>3 \mathrm{ml} / \mathrm{min} \text { and GFR }<3 \mathrm{ml} / \mathrm{min} \text { after } 18 \mathrm{months} \text { of PD. c Significant difference in the } \\
\text { same group before (basal) and } 18 \text { months after PD treatment. (Significant differences, } p<0.01 ; p<0.05 \text { ). }\end{array}$} \\
\hline
\end{tabular}

Monitored parameters of the participants, stratified by urine output and glomerular filtration rate (GFR) values at baseline and months 18, are described in Table 3. LVH was found in 32 of the patients with GFR $<3 \mathrm{ml} / \mathrm{min}$ but only in 7 patients with GFR $>3 \mathrm{ml} / \mathrm{min}$ before renal replacement therapy (RRT). After 18 months of PD LVH was 24 and 6 in patients with GFR $<3 \mathrm{ml} / \mathrm{min}$ and $>3 \mathrm{ml} / \mathrm{min}$, respectively $(\mathrm{p}<0.05)$. In group with GFR $>3 \mathrm{ml} / \mathrm{min}, \mathrm{LV}$ function was determined as significantly better after 18 months of PD (EF 62.2 $\pm 6.5 \%$, E/A ratio $1.1 \pm 0.1 ; \mathrm{p}<0.05)$. Daily urine volume, RRF, Kt/V urea weekly, systolic and diastolic $\mathrm{BP}$, CRP and BNP were significantly different between the two groups after 18 months of PD. NO was higher in the group with GFR $>3 \mathrm{ml} / \mathrm{min}$. Also, serum albumin was lower in the GFR $<3 \mathrm{ml} /$ min group during the follow-up, but not significantly (Table 3 ).

Furthermore, we performed linear regression analysis to examine which factors were independent predictors of changes in LVMi during the monitoring period (Table 4.). The model was statistically significant (Chi square $=37.0 ; \mathrm{p}<0.001$ ) and could explain between 52\% (R2 Cox and Snell) and 77\% (R2 Nagelkerkea) variance results and correctly classified $90 \%$ of cases. NO and RRF have proven to be independent factors both of increase 


\section{Kidney Blood Pressure Research}

Kidney Blood Press Res 2015;40:500-508

\begin{tabular}{l|l}
\hline DOI: $10.1159 / 000368526$ & (C) 2015 S. Karger AG, Basel
\end{tabular}

Published online: October 04, 2015

www.karger.com/kbr

Rebić/Sabljar Matovinović/Rašić/Kes/Hamzić-Mehmedbašić: Residual Renal Function and Peritoneal Dialysis
Table 4. Multiple regression analysis showing factors independently associated with decreased/increased left ventricular mass index in PD patients

\begin{tabular}{lccccc}
\hline \multicolumn{1}{c}{ Model } & B & $\begin{array}{c}\text { Standard } \\
\text { error }\end{array}$ & p-value & Exp(B) & $\begin{array}{c}\text { 95\% Confidence } \\
\text { Interval }\end{array}$ \\
\hline \multicolumn{5}{c}{ Decrease } \\
\hline NO & 0.132 & 0.050 & 0.008 & 0.877 & 0.795 to 0.967 \\
RRF & 2.395 & 0.725 & 0.001 & 10.966 & 2.647 to 45.433 \\
Endothelin-1 & -3.137 & 1.546 & .042 & 0.043 & 0.002 to 0.898 \\
\hline \multicolumn{7}{c}{ Increase } \\
\hline Diuresis (ml/24h) & 0.233 & 0.009 & 0.022 & 0.904 & 0.84 to 1.38 \\
NO & -0.103 & 0.034 & 0.003 & 0.755 & 0.641 to 0.882 \\
RRF & -0.132 & 0.021 & 0.036 & 0.174 & 0.229 to 0.418 \\
CRP & 0.133 & 0.067 & 0.004 & 0.091 & 1.003 to 1.302 \\
Hemoglobin & -3.781 & 0.122 & $<0.001$ & 0.965 & 1.782 to 3.189 \\
\hline \multicolumn{7}{c}{ Dependent variable: Left Ventricular Mass Index } \\
\hline Abbreviations: NO, nitric oxide; RRF, residual renal function; CRP, C-reactive protein. \\
The table shows only significant results. Other variables included: age, male gender, \\
diabetes, serum albumin, high peritoneal transport characteristics, daily ultrafiltration \\
volume, and total Kt/V.
\end{tabular}

and decrease of LVMi. In addition, in this statistical method included variables were age, male gender, diabetes, serum albumin, high peritoneal transport characteristic, daily ultrafiltration volume, and total Kt/V which showed no significant independent association with modifications of LVMi (Table 4).

\section{Discussion}

In the last decade, many researches have reached to the conclusion that preservation of RRF is important after initiating dialysis, as well as in the predialysis period. RRF has been proven to contribute to the quality of life of dialysis patients. Also, RRF has a major contribution to the delivery of adequate dialysis. The CANUSA study and the study by Davies et al. previously confirmed the importance of urea clearance and nutrition status in predicting the survival of PD patients $[9,10]$.

On the other hand, patients with chronic kidney disease (CKD) carry a high cardiovascular risk. In this patient group, cardiac structure and function are frequently abnormal and $74 \%$ of patients with CKD stage 5 have LVH at the initiation of renal replacement therapy (RRT). Cardiac changes, such as LVH and impaired LV systolic function have been associated with an unfavorable prognosis [11]. To our knowledge this is the first longitudinal study that describes an important and association between the degree of RRF and LVH in PD patients before RRT and after first years of dialysis treatment. Results of our study indicated that preservation of RRF was better, LVH was less frequent, and the LV systolic function was better after 18 months of PD.

Our results showed that the relation between RRF, total Kt/V and LVH was relevant in the first years of PD treatment. The decline in total Kt/V and RRF in the monitoring period of patients with increasing LVMi was associated with reduction of RRF but not statistically significant. ESRD patients before RRT with lower RRF (GFR $<3 \mathrm{~mL} / \mathrm{min}$ / $1.73 \mathrm{~m} 2$ ) had significantly greater presence LVH compared to those with better RRF (GFR $>3 \mathrm{~mL} / \mathrm{min} / 1.73 \mathrm{~m} 2$ ). Although a decrement RRF was associated with a frequent presentation $\mathrm{LVH}$, the expected compensatory increase in total $\mathrm{Kt} / \mathrm{V}$ has not occurred. Similar results were found in a study by Wang et al. [2]. The relationship between peritoneal transport characteristics which became apparent was not very pronounced during the monitoring period. Nevertheless, it appears likely that the relationship between the D/P [Cr] ratio, measured at the start of the study, and the change in RRF and LV structure during the follow-up period is explained by a reduced fluid removal caused by a higher permeability of the peritoneal membrane. Despite the rather weak correlation, these findings suggest that a more permeable peritoneal membrane is a risk factor for progressive overhydration, as could be expected theoretically. Such findings demonstrate the importance of the preservation of 


\section{Kidney Blood Pressure Research}

Kidney Blood Press Res 2015;40:500-508

DOI: $10.1159 / 000368526$

(C) 2015 S. Karger AG, Basel

www.karger.com/kbr

RRF and thereby improvements of the cardiac structure. At our center, only 3.3 percent of all PD patients are on automated PD (APD). Unfortunately, this fact represents a significant limitation in the treatment of high transporters PD patients. An analysis of patients in PD in Australia and New Zealand found a lower cardiovascular risk in high transporters treated with APD, compared with those on CAPD [12].

The prevalence of LVH was similar in our ESRD population (78\%) compared to studies by other authors (about 80\%). However, our results suggest even partial regression of LVH is possible after 18 months of PD therapy (prevalence 78\% vs. 60\%), as the recently Ardeleanu et al. demonstrated in patients on hemodialysis [13]. Namely, LVM and LVMi are modifiable factors, and their reduction decreases cardiovascular risk, especially in the dialysis population [14]. Important indicators of LVMi changes are hemodynamic and nonhemodynamic factors. In PD patients, the most prominent hemodynamic parameters are hypertension of high prevalence, volume overload and anemia [15].

The mechanisms which associate the level of RRF with the severity of LVH are likely multifactorial. One possible mechanism may be related to the reduced EPO production with a decline in RRF, as noted by the significant positive correlation between hemoglobin and GFR [16]. Patients with lower RRF were significantly more anemic. It should be note that all of our patients received substitution therapy epoetin (EPO) 4000-6000IU per week. Moreover, hemoglobin is demonstrated in our study as an independent negative predictor for increased LVMi. Anemia is a well-known cause of LVH in dialysis patients, and correction of anemia with EPO results in the partial regression of $\operatorname{LVH}[17,18]$. The greater resistance to the EPO's action and greater degree of anemia in patients with a worse RRF may be related to inadequate dialysis, secondary to the loss of RRF.

In our study, patients with increasing LVMi had a significant decline in diuresis compared to patients in whom LVMi decreased. The peritoneal ultrafiltration was not different between observed groups. This leads a reduced total fluid removal in patients with increasing LVMi versus those with decreasing LVMi. These results show an independent association RRF with any change of LVMi during the research period. In addition, daily diuresis is negative independent predictor of increased LVMi. These results lead to the opinion that besides inadequate removal of uremic toxins, overhydration could still be the main mechanism for progression of LVH in our study patients. Recently, Cader et al. clearly demonstrated that the overhydration is strongly associated with LVH in PD patients [19]. Furthermore, a recent study during a 6-month follow-up further supports the presumption of positive effect of volume control in dialysis patients using clinical routine by segmental calf bioimpedance spectroscopy (cBIS) for dry weight assessment. Also, myocardial mass and LVMi dropped constantly in that study [20].

The patients with preserved RRF (urine output $>500 \mathrm{ml}$ and GFR $>3 \mathrm{ml} / \mathrm{min} / 1.73 \mathrm{~m}^{2}$ at baseline and after 18 months) had lower levels of inflammatory markers and improved cardiac structure and function. Moreover, CRP was proved as an independent predictor for increased LVMi after 18 months of PD. Shafi, in his study on hemodialysis patients, showed that the presence of urine output was associated with lower levels of inflammatory markers [16]. CRP levels were lower in those with urine output compared with those without.

The results of our study suggest that patients with LVH compared to patient without LVH had increased ET-1 serum concentration as a potent vasoconstrictor and the decrease in NO level as vasodilatator. These results indicate that the influence of these vasoactive substances in the process of LV remodeling in PD patients. Our study confirmed significance independent relationship between LVH and serum concentration level of NO and ET-1 in PD patients during period of 18-month follow-up.

Our current findings together with recent study show that greater presence of LVH with worsening of cardiac performance in uremic patients before RRT suggest that the degree of uremia or reduced total urea and creatinine clearance secondary to loss of RRF may be responsible for the progressive cardiac hypertrophy.

Residual renal function also may play a role in limiting the increase of LVMi by improving the overall Kt/V and the removal of uremic toxins. This is evident by the increase of LVMi and 


\section{Kidney \\ Blood Pressure Research}

Kidney Blood Press Res 2015;40:500-508

\begin{tabular}{l|l}
\hline DOI: $10.1159 / 000368526$ & (c) 2015 S. Karger AG, Basel
\end{tabular}

Published online: October 04, 2015

www.karger.com/kbr

Rebić/Sabljar Matovinović/Rašić/Kes/Hamzić-Mehmedbašić: Residual Renal Function and Peritoneal Dialysis

decline in RRF in pre-dialysis chronic renal failure patients and the regression of LVH and the improvement of cardiac function in patients undergoing PD [21].

The fact that RRF, but not total Kt/V, showed a significant association with LVMi, together with previous studies [5] showing regression of LVH post-kidney transplant suggest that some non-dialyzable uremic toxins may be important in the progression of LVH. Recently, Shih et al. demonstrated in hemodialysis patients that the reduce intradialytic hypotension after parathyroidectomy may act as a braking system that prevents the vicious cycle of inadequate dialysis, fluid overload, and heart failure. Moreover, parathyroidectomy seems to reverse such adverse effects to achieve normotension and euvolemia, probably through improved heart function [22].

Diabetic uremic patients were not separately observed in this study because probably some of these patients have diabetic cardiomyopathy other than uremic cardiomyopathy, and it is difficult to separate these two entities only on the basis of their clinical status. In fact, these patients have a higher prevalence of vascular disease and silent ischemia, and more severe LVH [23]. However, it represents one of the most important limitations of this study. Also, number of patients studied was relatively small, which did not permit firm conclusions about differences between monitored parameters prior and 18 months after PD commencement. Furthermore, anuric patients were not observed in this study. A longer period of monitoring is needed in order to estimate a clear effect of PD on the preservation of RRF and its relation towards LV alterations. Finally, there is also a need for observation of PD patients after kidney transplantation.

\section{Conclusion}

This study provides evidence for several beneficial effects of RRF in PD patients. We have shown an important association between the degree of RRF and severity of LVH in ESRD patients undergoing PD. Its association with LVH appears to be mediated via mechanisms that are independent of its relationship with other known risk factors for LVH, serum concentration of nitric oxide and endothelin-1, anemia, malnutrition and inflammation, respectively. We demonstrated a strong and independent relationship between a simply obtained daily urine collection and RRF with changes of cardiac structure in the first years of PD. This highlights the usefulness of strategies oriented to preserve both RRF and optimize the fluid status of PD patients, as well as consequently a potential regression of LV remodeling. Renoprotective drugs and new glucose-sparing, more biocompatible PD regimes may prove useful tools to approach these problems. Overall, these results provide a strong rationale for routine monitoring of RRF in PD patients. Furthermore, the development of methods to assess and preserve RRF is important and may improve dialysis care.

\section{Disclosure Statement}

This manuscript was presented in part as abstract at the Annual Scientific Meeting of the American Society of Nephrology, ASN Kidney Week 2014, November 13-16, 2014, Philadelphia, PA, USA. All other authors declared no competing interests.

\section{References}

1 Lu YH, Hwang JC, Jiang MY, Wang CT: Comparison of the impact of "fast decline" in residual renal function and "initial anuria" on long-term outcomes in CAPD patients. Perit Dial Int 2015;35:172-179.

2 Wang AY, Woo J, Wang M, Sea MM, Sanderson JE, Lui SF, Li PK: Important differentiation of factors that 


\section{Kidney \\ Blood Pressure Research}

Kidney Blood Press Res 2015;40:500-508

\begin{tabular}{l|l}
\hline DOI: $10.1159 / 000368526$ & (C) 2015 S. Karger AG, Basel
\end{tabular}

Published online: October 04, 2015

www.karger.com/kbr

predict outcome in peritoneal dialysis patients with different degrees of residual renal function. Nephrol Dial Transplant 2005;20:396-403.

3 Han SS, Cho GY, Park YS, Baek SH, Ahn SY, Kim S, Chin HJ, Chae DW, Na KY: Predictive value of echocardiographic parameters for clinical events in patients starting hemodialysis. J Korean Med Sci 2015;30:44-53.

4 Lai S, Dimko M, Galani A, Coppola B, Innico G, Frassetti N, Mazzei ED, Mariotti A: Early markers of cardiovascular risk in chronic kidney disease. Ren Fail 2015; 37: 254-261.

5 Keven K, Calayoglu R, Sengul S, Dincer I, Kutlay S, Erturk S, Erbay B, Nergizoglu G: Comparative effects of renal transplantation and maintenance dialysis on arterial stiffness and left ventricular mass index. Clin Transplant 2008;22:360-365.

6 Devereux R, Alonso D, Lutas E, Gottlieb G, Compo E, Reichek N: Echocardiographic assessment of left ventricular hypertrophy: comparison to necropsy findings. Am J Cardiol 1986;57:450-458.

7 Watson PE, Watson ID, Batt RD: Total body water volumes for adult males and females estimated from simple anthropometric measurements. Am J Clin Nutr 1980;33: 27-39.

8 Chung SH, Chu WS, Lee HA, Kim YH, Lee IS, Lindholm B, Lee HB: Peritoneal transport characteristics, comorbid diseases and survival inCAPD patients. Perit Dial Int 2000;20:541-547.

9 CANADA-USA (CANUSA). Peritoneal dialysis study group: Adequacy of dialysis and nutrition in continuous peritoneal dialysis: Association with clinical outcomes. J Am Soc Nephrol 1996;7:198-207.

10 Davies SJ, Phillips L, Naish PF, Russell GI: Quantifying comorbidity in peritoneal dialysis patients and its relationship to other predictors of survival. Nephrol Dial Transplant 2002;17:1085-1092.

11 Chiu DY, Green D, Abidin N, Sinha S, Kalra PA: Cardiac imaging in patients with chronic kidney disease. Nat Rev Nephrol 2015;11:207-220.

12 Johnson DW, Hawley CM, McDonald SP, Brown FG, Rosman JB, Wiggins KJ, Bannister KM, Badve SV: Superior survival of high transporters treated with automated versus continuous ambulatory peritoneal dialysis. Nephrol Dial Transplant 2010;25:1973-1979.

13 Ardeleanu Ş, Panaghiu L, Prisadă O, Sascău R, Voroneanu L, Hogaş S, Mardare N, Covic A: Regression of left ventricular hypertrophy in hemodialyzed patients is possible: a follow-up study. Int Urol Nephrol 2011;43:1161-1169.

14 Zoccali C, Benedetto FA, Mallamaci F, Tripepi G, Giacone G, Stancanelli B, Cataliotti A, Malatino LS: Left ventricular mass monitoring in the follow-up of dialysis patients: prognostic value of left ventricular hypertrophy progression. Kidney Int 2004;65:1492-1498.

15 London GM: Left ventricular alterations and end-stage renal disease. Nephrol Dial Transplant 2002;17:29-36.

16 Shafi T, Jaar BG, Plantinga LC, Fink NE, Sadler JH, Parekh RS, Powe NR, Coresh J: Association of residual urine output with mortality, quality of life, and inflammation in incident hemodialysis patients: the Choices for Healthy Outcomes in Caring for End-Stage Renal Disease (CHOICE) Study. Am J Kidney Dis 2010;56:348-358.

17 Schmid H, Schiffl H, Lederer SR: Erythropoiesis-stimulating agents, hypertension and left ventricular hypertrophy in the chronic kidney disease patient. Curr Opin Nephrol Hypertens 2011;20:465-470.

18 Kirkpantur A, Kahraman S, Yilmaz R, Arici M, Altun B, Erdem Y, Yasavul U, Turgan C: The effects of maintenance recombinant human erythropoietin therapy on ambulatory blood pressure recordings: conventional, Doppler, and tissue Doppler echocardiographic parameters. Artif Organs 2005;29:965-972.

19 Cader RA, Ibrahim OA, Paul S, Gafor HA, Mohd R: Left ventricular hypertrophy and chronic fluid overload in peritoneal dialysis patients. Int Urol Nephrol 2014;46:1209-1215.

20 Seibert E, Müller SG, Fries P, Pattmöller J, Kuss O, Heine GH, Girndt M, Schneider G, Kotanko P, Zhu F, Levin NW, Kuhlmann MK: Calf bioimpedance spectroscopy for determination of dry weight in hemodialysis patients: effects on hypertension and left ventricular hypertrophy. Kidney Blood Press Res 2013;37:58-67.

21 Wang H, Liu J, Yao XD, Li J, Yang Y, Cao TS, Yang B: Multidirectional myocardial systolic function in hemodialysis patients with preserved left ventricular ejection fraction and different left ventricular geometry. Nephrol Dial Transplant 2012;27:4422-4429.

22 Shih CJ, Tarng DC, Yang WC, Yang CY: Parathyroidectomy reduces intradialytic hypotension in hemodialysis patients with secondary hyperparathyroidism. Kidney Blood Press Res 2013;37:323-331.

23 Drechsler C, Kalim S, Wenger JB, Suntharalingam P, Hod T, Thadhani RI, Karumanchi SA, Wanner C, Berg $\mathrm{AH}$ : Protein carbamylation is associated with heart failure and mortality in diabetic patients with end-stage renal disease. Kidney Int 2015;87:1201-1208. 